classify IIM in comparison with 1975 Bohan and Peter criteria in Chinese patients.

Methods: Two hundred and twenty-one in-patients with suspected IIM (including 40 children) were retrospectively included in this study. The performance of 2017 EULAR/ACR criteria was evaluated by sensitivity, specificity, positive predictive value, negative predictive value and classification rate, in comparison to the 1975 criteria, with clinical diagnosis as the gold standard.

Results: The sensitivity, specificity, positive predictive value, negative predictive value of the 2017 EULAR/ACR criteria in IIM classification were $92.7 \%, 87.0 \%, 90.1 \%$ and $90.4 \%$ respectively, in contrast to the 1975 Bohan and Peter criteria of $84.0 \%, 52.2 \%, 61.8 \%$, and $77.9 \%$ (Fig 1). The classification rate of 2017 criteria was also much better than that of 1975 criteria $(90.2 \%$ vs. $67.4 \%)$. The performance of the new criteria in general, as well as the new criteria with muscle biopsy was better. Most IIM patients were correctly further subclassified by the classification tree. The positive rate of myogenic lesion in electromyography (EMG), muscular inflammatory edema in magnetic resonance Imaging (MRI) and specific antibodies of myositis were significantly higher in IIM group than those in control group $(\mathrm{p}<0.001$, all).

Conclusion: The 2017 EULAR/ACR criteria exhibited high sensitivity, specificity, classification rate in the Chinese IIM patients, which was superior to the 1975 criteria. The new criteria showed potentials as clinical classification criteria in the future.

Figure 1. Performance of 2017 EULAR/ACR criteria and 1975 Bohan and Peter criteria. - Sensitivity Specificity
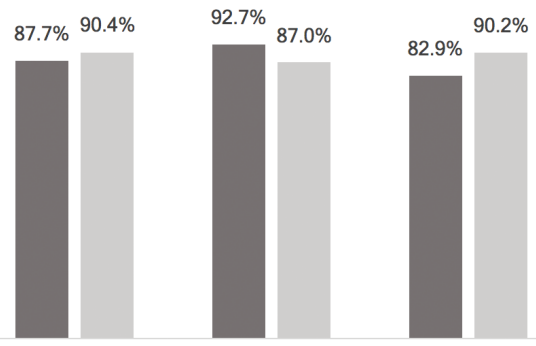

$84.0 \%$

2017 EULAR/ACR 2017 criteria* criteria With muscle biopsy

\section{C17 EULAR/ACR} muscle biopsy

* referred to the overall assessment, including patients "score of $\geq 5.5$ without biopsies and score of $\geq 6.7$ with biopsies

\section{REFERENCES}

[1] Bohan A, Peter JB: Polymyositis and dermatomyositis (first of two parts). N Engl J Med 1975, 292:344-347.

[2] Bohan A, Peter JB: Polymyositis and dermatomyositis (second of two parts). N Engl J Med 1975, 292:403-407.

[3] Lundberg IE, Tjarnlund A, Bottai M, Werth VP, Pilkington C, de Visser M, Alfredsson L, Amato AA, Barohn RJ, Liang MH, et al: 2017 European League Against Rheumatism/American College of Rheumatology Classification Criteria for Adult and Juvenile Idiopathic Inflammatory Myopathies and Their Major Subgroups. Arthritis Rheumatol 2017, 69:2271-2282.

[4] Lundberg IE, Tjarnlund A, Bottai M, Werth VP, Pilkington C, Visser M, Alfredsson L, Amato AA, Barohn RJ, Liang MH, et al: 2017 European League Against Rheumatism/American College of Rheumatology classification criteria for adult and juvenile idiopathic inflammatory myopathies and their major subgroups. Ann Rheum Dis 2017, 76:1955-1964.

Disclosure of Interests: None declared

DOI: 10.1136/annrheumdis-2019-eular.2716

\section{AB0697C THE ASSOCIATION OF ANTI-MELANOMA DIFFERENTIATION-ASSOCIATED PROTEIN 5 AND SEASONAL PATTERNS IN ONSET OF IDIOPATHIC INFLAMMATORY MYOPATHIES IN KOREA}

In Seol Yoo, Jinhyun Kim, Seong Wook Kang, Su-Jin Yoo, Seungcheol Shim, Chan Keol Park. Chungnam National University Hospital, Division of

Rheumatology, Department of Internal Medicine, Daejeon, Korea, Rep. of (South Korea)

Background: There was some reports of seasonal association with myopsitis onset. With the discovery of new myositis-specific autoantibodies
(MSA), detailed grouping of idiopathic inflammatory myopathies was possible. Therefore, we evaluated the seasonal patterns in the onset of idiopathic inflammatory myositis (IIM) with MSA in Korea.

Objectives: To evaluate the correlation between MSA and seasonal patterns of IIM in Korea.

Methods: A total of 90 patients who met the criteria for probable or definite PM or DM and for whom data were collected from 7 referal centers in korea. 16 myositis-specific autoantibodies were detected by immunoblot with patient's serum. Statistical analyses were performed using a Poisson model that assessed associations of sex, MSA, and month of onset of symptoms or month of diagnosis.

Results: There were no significant seasonal patterns of disease onset in total IIM patients. Among MSAs, anti-synthetase $(n=18)$, anti-transcriptional intermediary factor $1 \gamma(\mathrm{TIF} 1 \gamma)(\mathrm{n}=13)$, anti-melanoma differentiation-aasocianted protein 5 (anti-MDA5) ( $\mathrm{n}=12)$, and anti-signal recognition particle (SRP) $(n=12)$ were analyzed. Among 55 patients with dermatomyositis, patients with anti-MDA5 showed a significant peak in winter $(n=12$ $P=0.05$ ). This seasonal association was significant in women ( $n=10$ $\mathrm{P}=0.045$ ). Patients with anti-synthetase, anti-TIF1 $\gamma$ or anti-SRP antibodies did not have a significant seasonal onset patterns. There were no significant seasonal patterns in patients without myositis-specific autoantibodies. Conclusion: Patients with anti-MDA5 showed a seasonality of myositis onset, in winter.

Disclosure of Interests: None declared

DOI: 10.1136/annrheumdis-2019-eular.6579

\section{AB0697D \\ CARDIOVASCULAR RISK FACTORS ARE HIGHER IN MALNOURISHED PATIENTS WITH SYSTEMIC SCLEROSIS}

${ }^{1}$ Anna Wojteczek ${ }^{*}$, Marcin Ziętkiewicz ${ }^{1}$, Zbigniew Zdrojewski ${ }^{1}$

Sylwia Małgorzewicz ${ }^{2} .{ }^{1}$ Medical University of Gdańsk, Department of Internal Medicine, Connective Tissue Diseases and Geriatrics, Gdańsk, Poland; ${ }^{2}$ Medical University of Gdańsk, Department of Clinical Nutrition, Gdańsk, Poland

Background: Cardiovascular disease (CVD) is a well known complication in rheumatoid arthritis and systemic lupus erythematosus. Atherosclerosis (ATS) and its impact on CVD in patients with systemic sclerosis (SSc) still remains unclear. Most of studies are suggesting higher frequency of CVD in SSc in comparison to healthy controls. CVD is a leading cause of death in most developed countries, whereas in SSc population it ranges from 20 to $30 \%$. The etiology of ATS in SSc is unknown. Traditional risk factors, endothelial dysfunction and inflammation can contribute to ATS in SSc population. However there is lack of data about the impact of the nutritional status on CVD factors in SSc patients.

Objectives: The aim of the study was to determine CVD factors among SSc patients depending on the nutritional status.

Methods: In 55 patients with SSc $(72,7 \%$ well-nourished, $18,1 \%$ malnourished, $9,1 \%$ pre-cachexia) and 49 healthy controls we measured markers of endothelial dysfunction (asymmetric dimethylarginine - ADMA), inflam mation (C-reactive protein - CRP, high sensitivity C-reactive protein hsCRP, interleukin 6 - IL-6) and dyslipoproteinemia (oxidized low-density lipoprotein - ox-LDL, high-density lipoprotein- HDL, low-density lipoprotein - LDL and total cholesterol). Nutritional status was determined with subjective global assessment (SGA), body mass index (BMI), bioelectrica impedance analysis (BIA) and anthropometric measurements.

Results: Well-nourished SSc patients had significantly higher level of IL-6 $(6,4 \pm 10,1$ vs. $2,8 \pm 3,6 \mathrm{pg} / \mathrm{ml} ; \mathrm{p}=0,002)$ and lower HDL cholesterol $(49,9$ $\pm 11,6$ vs. $57 \pm 13,6 \mathrm{mg} / \mathrm{dl} ; \mathrm{p}=0,011)$ in comparison to healthy control. In malnourished SSc patients there was higher concentration of ADMA $(1,68$ $\pm 0,53$ vs. $1,24 \pm 0,34 \mu \mathrm{mol} / \mathrm{l} ; \mathrm{p}=0.003)$, $\operatorname{CRP}(18 \pm 28,8$ vs. $2,4 \pm 2,5 \mathrm{mg} / \mathrm{l}$; $\mathrm{p}=0.04)$, IL-6 $(21,6 \pm 34,9$ vs. $2,8 \pm 3,6 \mathrm{pg} / \mathrm{ml} ; \mathrm{p}=0.004)$ and lower HDL cho lesterol $(42,5 \pm 18,3$ vs. $57 \pm 13,6 \mathrm{mg} / \mathrm{dl} ; \mathrm{p}=0.01)$ in comparison to healthy control. Pre-cachexia SSc group had significantly lower total cholesterol $(166,8 \pm 28,5$ vs. $219,3 \pm 40,9 \mathrm{mg} / \mathrm{dl} ; \mathrm{p}=0.008)$ and LDL cholesterol $(96,8$ $\pm 21,6$ vs. $139,6 \pm 36 \mathrm{mg} / \mathrm{dl} ; \mathrm{p}=0.007$ ). There were no differences in concentration of oxLDL and hsCRP in those groups.

Conclusion: Nutritional status may play role in risk of CVD in SSc patients. Although its contribution to morbidity and mortality rates in CVD in SSc is yet to be established.

Disclosure of Interests: None declared

DOI: 10.1136/annrheumdis-2019-eular.8086 


\section{Spondyloarthritis - treatment}

\section{AB0698 EFFECTIVENESS AND SAFETY OF CERTOLIZUMAB PEGOL FOR THE TREATMENT OF AXIAL SPONDYLOARTHRITIS IN REAL-WORLD CLINICAL PRACTICE IN EUROPE: RESULTS FROM A PROSPECTIVE NON-INTERVENTIONAL 12-MONTH COHORT STUDY}

${ }^{1}$ Xenofon Baraliakos ${ }^{*}$, Torsten Witte ${ }^{2}$, Luc De Clerck ${ }^{3}$, Bruno Frediani ${ }^{4}$, Eduardo Collantes-Estévez ${ }^{5}$, Gkikas Katsifis ${ }^{6}$, Brenda Vanlunen ${ }^{7}$, Elisabeth Kleine ${ }^{8}$, Bengt Hoepken ${ }^{8}$, Nicola Goodson ${ }^{9} .{ }^{1}$ Rheumazentrum Ruhrgebiet Herne, Ruhr-University Bochum, Bochum, Germany; ${ }^{2}$ Hannover Medical School, Hannover, Germany; ${ }^{3}$ Antwerp University Hospital, Antwerp, Belgium; ${ }^{4}$ University of Siena, Siena, Italy, ${ }^{5}$ Reina Sofia University Hospital, Córdoba, Spain; ${ }^{6}$ Naval Hospital of Athens, Athens, Greece; ${ }^{7}$ UCB Pharma, Raleigh, NC, United States of America; ${ }^{8}$ UCB Pharma, Monheim, Germany; ${ }^{9}$ Aintree University Hospital NHS Foundation Trust, Liverpool, United Kingdom

Background: Certolizumab pegol (CZP) is an Fc-free, PEGylated anti-TNF with an established efficacy and safety profile in axial spondyloarthritis (axSpA) in clinical trial settings. ${ }^{1}$

Objectives: To report CZP effectiveness and safety in patients (pts) with axSpA, including ankylosing spondylitis (AS; radiographic axSpA) and nonradiographic (nr-) axSpA subpopulations, in routine clinical practice in Europe. Methods: CIMAX (NCT02354105) was a non-interventional multicentre prospective cohort study observing CZP treatment response and safety over 12 months in a real-world clinical cohort of axSpA pts newly prescribed CZP. The primary outcome was change from baseline (CFB) in Bath Ankylosing Spondylitis Disease Activity Index (BASDAl) to Week (Wk) 52 in pts with available data, with additional outcomes pertaining to effectiveness and safety. Outcomes were evaluated for AS and nr-axSpA subpopulations (diagnosed according to local practice). Pts who received $\geq 1$ dose CZP were followed up for adverse events (AEs) (Safety Set [SS]); those with baseline and $\geq 1$ post-baseline BASDAl assessment were included in the effectiveness analyses (Full Analysis Set [FAS]). Outcomes are reported using observed case data with no imputation.

Results: 682 axSpA pts were enrolled from 101 European sites, of whom $490(71.8 \%)$ completed the study. Of those enrolled, 672 formed the SS (AS: 469; nr-axSpA: 201) and 564 the FAS (AS: 384; nr-axSpA: 179); 2 (SS)/1(FAS) pts with unconfirmed AS/nr-axSpA were included in the overall axSpA population. $27.5 \%$ (185/672[SS]) axSpA pts had previous anti-TNF exposure (AS: $31.1 \%$ [146/469]; nr-axSpA: 18.4\% [37/201]). BASDAl data were available for $77.8 \%$ (439/564) pts at Wk52. In pts with available data, all clinical outcomes were improved at Wk52 in both subpopulations (Table). At baseline, the mean BASDAl was 6.1. At Wk52, the mean BASDAI CFB in pts with available data $(n=439)$ was -2.9 (AS: -2.9 [ $n=301$ ]; nr-axSpA: $-2.8[n=137])$. For pts with and without prior anti-TNF exposure, BASDAl at baseline was 6.1 in both groups ( $n=165$ vs $n=399$, respectively), and at Wk52, the mean BASDAI CFB was $-2.6(n=127)$ vs -3.0 $(n=312)$ (AS: -2.7 vs -3.0 ; nr-axSpA: -2.2 vs -3.0 ). In the SS, $37.9 \%$ (255/672) pts experienced AEs; $20.7 \%$ (139/672) experienced drug-related AEs and 6.3\% (42/672) serious AEs (1.8\% [12/672] reported serious infections); these data were comparable between AS and nr-axSpA (Table).

Conclusion: This is the first multicentre European study to evaluate CZP effectiveness and safety in both axSpA subpopulations in routine practice. Improvements were observed in all signs and symptoms in pts who remained on treatment to Wk52; $>70 \%$ of those enrolled completed the study. No new safety signals were identified following application of CZP to real-world rheumatological practice.

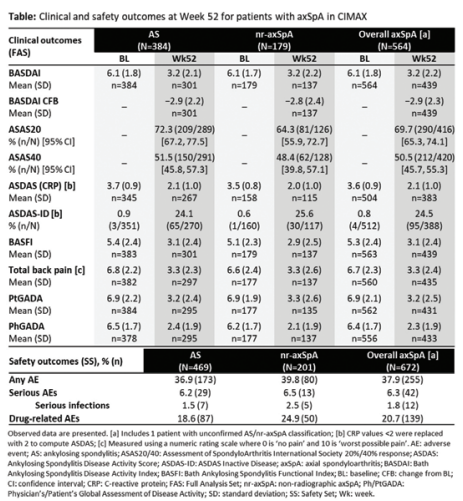

\section{REFERENCES}

[1] van der Heijde D. Rheumatology (Oxford) 2017;56:1498-509.

Acknowledgement: We thank the patients who participated. This study was funded by UCB Pharma, medical writing by Jessica Patel, Costello Medical, UK

Disclosure of Interests: Xenofon Baraliakos Grant/research support from: AbbVie, Boehringer Ingelheim, Bristol-Myers Squibb, Celgene, Centocor, Chugai, Janssen, MSD, Novartis, Pfizer Inc, Roche and UCB, Grant/ research support from: AbbVie, Pfizer, Merck Sharp \& Dohme, UCB Pharma, Novartis, Consultant for: AbbVie, Bristol-Myers Squibb, Boehringer Ingelheim, Celgene, Chugai, Janssen Biologics, Novartis, Pfizer, UCB Pharma, Galapagos, Speakers bureau: AbbVie, Chugai, Janssen, Novartis, Pfizer, UCB Pharma, Torsten Witte Consultant for: UCB Pharma, Luc De Clerck Grant/research support from: Abbvie, MSD, Roche, Pfizer, Bruno Frediani: None declared, Eduardo Collantes-Estévez Consultant for: UCB Pharma, MSD, AbbVie, Novartis, Janssen, Gkikas Katsifis Consultant for: UCB Pharma, Janssen, Abbvie, Novartis, MSD, Aenorasis, Genesis Pharma, Pfizer, Roche, Brenda VanLunen Employee of: Employee of UCB Pharma, Elisabeth Kleine Employee of: Employee of UCB Pharma, Bengt Hoepken Employee of: Employee of UCB Pharma, Nicola Goodson Grant/research support from: Novartis, Speakers bureau: AbbVie, Janssen, UCB Pharma

DOI: 10.1136/annrheumdis-2019-eular.1707

\section{AB0699 EFFECT OF SWITCHING BETWEEN TUMOR NECROSIS FACTOR INHIBITOR IN SPONDYLOARTHRITIS}

hedia ben abla, Sonia Rekik, Soumaya Boussaid, Samia Jammali, Hela Sahli, Elhem Cheour, Mohamed Elleuch. la rabta, tunis, Tunisia

Background: The introduction of new drugs, in particular tumour necrosis factor inhibitor (TNFi) has revolutionized the treatment of spondyloarthritis (SpA). Meanwhile, about $30 \%$ of patients do not react to first-line TNFi. To date,there is no recommendations available forthe treatment of SpA patients after first TNFi failure.

Objectives: In this study we assessed the effectiveness of a second and third biotherapy in patients with $\mathrm{SpA}$ with an inadequate response to previous TNFi and to analyze the survival of the second biotherapy

Methods: This study included patients with SpA who had had at least two biotherapies. Treatment response was noted at 3 months. At 6 months, we assessed the maintaining of effectiveness in Spa. We studied the elements of a good response to the second biotherapy.

Results: Our population of study included $30 \mathrm{SpA}$. During the second treatment, response rate was achieved by $80 \%$ after 3 months. No difference was noted between first and second TNFi among switchers. 86 $7 \%$ maintained response at twelve months. For axial forms, decrease in BASDAI was significant at 3 months. For peripheral forms, an improvement of the swollen and tender joint counts was observed and was significant at 3 months. Four patients have received a third TNFi. Response rate was achieved by all of them after 3 months. All of them maintained response at 6 months. The elements of a good response founded were;the early age of the $\operatorname{SpA}$ starting $(<30 y .0)$, the high value of initial CRP,the use of ESSG criteria,the SpA type,the extra articular signs, the first biotherapy and the reponse at 3 months to it, the drugs taken when second biotherapy were initiated a low initial EVA and BASFI.

Conclusion: These real-life data show that, after discontinuation of a first $\mathrm{TNFi}$, switching to a second biotherapy in $\mathrm{SpA}$ is related to significantly improving of clinical effectiveness compared to a first TNFi.

\section{REFERENCES}

none

Disclosure of Interests: None declared

DOI: 10.1136/annrheumdis-2019-eular.3834 